\title{
INCLUSÃO ESCOLAR DE ESTUDANTES COM TRANSTORNO DO ESPECTRO AUTISTA (TEA) NO ENSINO FUNDAMENTAL II
}

\author{
INCLUSIÓN ESCOLAR DE ESTUDIANTES CON TRANSTORNO DEL \\ ESPECTRO AUTISTA (TEA) EN LA ENSEÑANZA FUNDAMENTAL II
}

\author{
SCHOOL INCLUSION OF STUDENTS WITH AUTISTIC SPECTRUM \\ DISORDERS (ASD) IN SECONDARY LEVEL EDUCATION II
}

\author{
Regiane Cristina CÁBRIO ${ }^{1}$ \\ Relma Urel Carbone CARNEIRO ${ }^{2}$
}

RESUMO: Este estudo apresenta uma reflexão sobre a inclusão escolar de alunos com Transtorno do Espectro Autista TEA, clientela pertencente ao público alvo da Educação Especial, discutindo essa realidade no Ensino Fundamental II. Apresenta uma visão geral sobre o TEA e a análise de uma entrevista semiestruturada realizada com um professor que possuía um aluno com TEA, verificando qual sua visão sobre seu papel e como o aluno é visto e trabalhado na escola. Utilizamos uma abordagem qualitativa de pesquisa e como procedimento metodológico o Estudo de Caso. Buscamos verificar como tem se dado a inclusão nesta realidade. Após a análise dos dados constatou-se que ainda há muitos aspectos que devem ser mudados para que ocorra uma inclusão efetiva, principalmente na formação do grupo gestor, dos docentes, e inciativas governamentais, a fim de que a inclusão seja sinônimo de desenvolvimento e aprendizagem significativos.

PALAVRAS-CHAVE: Inclusão escolar. Autismo. Ensino fundamental II.

RESUMEN: Este estudio presenta una reflexión acerca de la inclusión de alumnos con Trastorno del Espectro Autista TEA, clientela perteneciente al público objetivo de la Educación Especial, discutiendo esta realidad en la Enseñanza Fundamental II. Presenta una visión general acerca de lo TEA y la analice de una entrevista semiestructurada realizada con un profesor que poseía un alumno con TEA, verificando cuál su visión acerca de su papel y como el alumno es mirado y trabajado en la escuela. Utilizamos un abordaje cualitativo de investigación y como procedimiento metodológico el Estudio de caso. Buscamos verificar como ha ocurrido la inclusión en esta realidad. Después de la análisis de los dados se constató que aun hay muchos aspectos que deben ser cambiados para que ocurra una inclusión efectiva, principalmente en la formación del grupo gestor, de los docentes, y iniciativas gubernamentales, afín de que la inclusión sea sinónimo de desarrollo y aprendizaje significativos.

\footnotetext{
1 Universidade Estadual Paulista (Unesp), Araraquara - SP - Brasil. Professora efetiva de Língua Portuguesa do Estado de São Paulo. E-mail: regianecabrio@gmail.com.

${ }^{2}$ Universidade Estadual Paulista (Unesp), Araraquara - SP - Brasil. Prof. Dra. do Departamento de Psicologia da Educação e do Programa de Pós-graduação em Educação Escolar, Faculdade de Ciências e Letras. E-mail: relmaurel@fclar.unesp.br
} 
PALABRAS CLAVE: Inclusión escolar. Autismo. Enseñanza fundamental II.

ABSTRACT: This paper presents a reflection about the school inclusion of students with Autistic Spectrum Disorder (ASD), that are the target public of special education, discussing this reality at Secondary Level Education II. Provides an overview about the $A S D$ and the analyses of an interview semi structured with a teacher that had a student with ASD, verifying what is his vision about his role and how the student is seen and dealt with at school. We utilized a qualitative approach of research and as methodological procedure the Case Study. We aimed to verify how the inclusion has been occurring in this reality. After the analysis of the data it was perceptible that there are still lots of aspects that must be changed for an effective inclusion, especially at the formation of the managing group, the teachers, and governmental measures, so that inclusion can be a synonym of development e meaningful learning.

KEYWORDS: School inclusion. Autism. Secondary level education II.

\section{Introdução}

O termo autismo é de origem grega, onde "autos" significa "de si mesmo", ou seja, alguém que está voltado para si mesmo. Foi introduzido em 1906, pelo psiquiatra Plouller para descrever sinais de isolamento em alguns casos clínicos, e em 1943, Kanner descreveu o mesmos sinais com outra terminologia: "distúrbio austístico do contato afetivo”. Desde então várias modificações foram feitas no conceito, casos com características comuns foram agrupados e denominados de Transtornos Globais do Desenvolvimento - TGD. Recentemente separaram do TGD o Autismo e a Síndrome de Asperger, que foram agrupados no Transtornos do Espectro do Autismo - TEA. Foram várias as terminologias criadas por diferentes teóricos com a finalidade de estudar o autismo, o mesmo acontece com a descrição deste.

Para o psiquiatra austríaco Kanner (1943), o que mais se destaca no estudo do fenômeno é a incapacidade das crianças no estabelecimento de relações com outras pessoas desde que nascem e de sua incapacidade de construir contato afetivo. Descrição esta que hoje é questionável, pois o autista não é incapaz de construir contato afetivo, o contato construído por ele é diferente do padrão.

Outros teóricos como Rutter (1967), Ritvo e Freedman (1978), Wing (1988), Mazet e Stoleru (1990), Ajuriaguerra e Marcelli (1991) também contribuíram com suas definições e estudos acerca do autismo. Em 1997, Gauderer, formulou o seguinte conceito: 
[...] é uma doença grave, crônica, incapacitante, que compromete o desenvolvimento normal de uma criança e se manifesta tipicamente antes do terceiro ano de vida. Caracteriza-se por lesar e diminuir o ritmo do desenvolvimento psiconeurológico, social e linguístico. Estas crianças também apresentam reações anormais e sensações diversas como ouvir, ver, tocar, sentir, equilibrar e degustar. A linguagem é atrasada ou não se manifesta. Relacionam-se com pessoas, objetos ou eventos de uma maneira não usual, tudo levando a crer que haja um comprometimento orgânico do Sistema Nervoso Central.” (p. 75)

Buscando uma abordagem mais objetiva, a Organização Mundial da Saúde (OMS) define o autismo como doença, identificando-a pelo CID 10 e estabelece meios de identificação, como é possível perceber no excerto abaixo exposto:

um transtorno invasivo, definido pela presença de desenvolvimento anormal e/ou comprometimento que se manifesta antes da idade de 3 anos e pelo tipo característico de funcionamento anormal em todas as três áreas: de interação social, comunicação e comportamento restrito e repetitivo. $O$ transtorno ocorre três a quatro vezes mais frequentemente em garotos do que em meninas.

A OMS estimou, em 2015, que existia 70 milhões de autistas em todo o mundo, constituindo $1 \%$ da população. Sendo que, deste percentual, 2 milhões encontram-se no Brasil. Em comparação com o Censo de 2000, em que foi detectada uma prevalência entre 2 e 5 casos para 10.000 habitantes, estimando-se, assim, os autistas, em cerca de 500 mil, percebe-se o aumento exponencial que essa deficiência teve em 15 anos, o que justifica a importância da sua análise no ambiente pedagógico e social promovida pela escola.

A origem do autismo, segundo algumas pesquisas de paradigma biológico, é uma combinação de defeitos genéticos com substâncias tóxicas. Outras, porém, alegam que a deficiência pode ser uma reação adversa causada pela vacinação, que ocorre durante os primeiros 18 meses de vida. Todavia, considerando que ainda não há exames biológicos para diagnosticar o transtorno autista, outros instrumentos são utilizados para este fim, sendo a anamnese e o quadro clínico os mais comuns. Para unificar o diagnóstico foram criadas várias escalas e critérios como o CARS (Childhood Autism Rating Scale), o BOS (Behavior Observation Scale for Autism), o ASIEP (Autism Screening Instrument for Educational Planning), o CHAT (Checklist for Autism in Toddlers), o IBSE (Behavioral Summarized Evaluation Scale) e o ADI-R (Autism diagnostic interview-revised). 
Assim, confirmado o diagnóstico, o tratamento deverá ser realizado por uma equipe multidisciplinar, com o objetivo de minimizar os danos, considerando que não há uma cura para o TEA. Mas, na busca por remédios que melhore o tratamento, a indústria farmacêutica tem investido em pesquisas para compreender como funcionam os diferentes circuitos cerebrais envolvidos nas funções sociais. Deste modo, a conjugação de tratamento por remédios com a atuação da equipe multidisciplinar objetiva torna os indivíduos com TEA mais independentes.

Os sujeitos com TEA requerem atenção especial por apresentarem determinados sintomas típicos tais como: irritabilidade, desatenção, hiperatividade / impulsividade, agressividade, insônia, e comportamentos repetitivos. Além disso, aproximadamente $20 \%$ deles apresentam epilepsia. Esses sintomas fizeram que, por muito tempo, houvesse a separação entre alunos regulares e alunos com TEA, de modo que somente a partir de 2008, com a elaboração da Política Nacional de Educação Especial na Perspectiva da Educação Inclusiva, é que estas crianças deixaram de ser segregadas em salas especiais e passaram a ser incluídas nas salas regulares do ensino básico.

Essa política motivou a criação e aprovação da Lei no 12.764/2012, também conhecida como Lei Berenice Piana a qual, ressalta o direito à educação inclusiva e ao Atendimento Educacional Especializado - AEE, confirmando acesso a todos os níveis de ensino em todo o país. Ainda, confere o direito de receberem atendimento específico no contra turno da aula regular durante sua vida escolar, incluindo aqui a qualificação aos gestores escolares e professores.

Desde então, o número de alunos com TEA matriculados no ensino básico regular tem aumentado. Entretanto, é importante salientar que as crianças com TEA apresentam nível de gravidade diferente, algumas apresentam muita dificuldade em se expressar e não falam, outras fazem movimentos repetitivos e evitam contato com as pessoas, uma parte apresenta deficiência intelectual, e temos ainda o autismo de alto desempenho que tem uma habilidade extremamente desenvolvida.

Sendo assim, o educador precisa conhecer as características básicas de cada transtorno ou síndrome, além de possuir condições de desenvolver estratégias pedagógicas diferenciadas para cada nível a fim de oferecer uma aprendizagem significativa.

A convivência da diversidade proporciona à criança que tenha necessidade educacionais especiais maior probabilidade de desenvolvimento acadêmico e social. Proporciona, ainda, para todos, alunos e professores, com e sem necessidades educacionais especiais, 
a prática saudável e educativa na convivência na diversidade e da administração das diferenças no exercício das relações interpessoais aspecto fundamental da democracia e da cidadania." (FONSECA, 2004, p. 27)

O convívio com a diversidade proporciona a todos nós a ideia de compartilhar e aceitar as particularidades de cada um, tornando-nos mais solidários e acolhedores, e isto faz parte do processo de inclusão. Ressalta-se que a inclusão escolar é um tema recente em nosso meio e na educação ainda mais, exigindo da sociedade um esforço adicional para romper paradigmas sociais, abandonar pré-conceitos de que o deficiente é um indivíduo inútil para acreditarmos que ele é diferente, mas capaz de superar limites.

Desse modo, o objetivo geral do presente estudo foi analisar a inclusão escolar dos alunos com TEA, a partir da visão do professor por meio da realização de uma entrevista semiestruturada, cujo detalhamento se dará na metodologia. Além disso, como objetivo específico foi verificado se a inclusão está ocorrendo efetivamente ou não, se a formação docente é apropriada para realizar um trabalho que leve o aluno com TEA a desenvolver suas habilidades e superar seus limites ou se a escola funciona como simples catalisador para a convivência social.

\section{Método}

Este estudo seguiu uma abordagem de pesquisa qualitativa. O problema e os objetivos propostos para a pesquisa levaram-nos a utilizar como procedimento metodológico o Estudo de Caso, por compreendermos que atende aos objetivos definidos neste estudo. Na visão de (LUDKE; ANDRÉ, 1986, p. 17), o estudo de caso é sempre bem delimitado, devendo ter seus contornos claramente definidos no desenrolar do estudo. [...] O interesse incide naquilo que ele tem de único, de particular, mesmo que posteriormente venham a ficarem evidentes certas semelhanças com outros casos ou situações. Para o desenvolvimento da parte empírica do estudo a técnica utilizada para coleta dos dados foi a aplicação de uma entrevista semiestruturada.

A entrevista foi realizada com um professor que ministrava a disciplina de História em uma turma do $8^{\circ}$ ano do EF II da rede pública de ensino de uma cidade de porte médio do interior do estado de São Paulo, que possuía em sua turma um aluno com TEA. A escola participante é da rede estadual de ensino, atuava com dois turnos de funcionamento, no período da manhã tendo o Ensino Médio com 8 salas e, no período da tarde, o Ensino Fundamental II com 7 salas em funcionamento. 


\section{Análise e discussão dos dados}

A partir da organização das respostas dadas a cada uma das questões e da leitura sistemática das mesmas foi possível analisar, ainda que de forma pontual, como tem se dado a inclusão do aluno com TEA, no Ensino Fundamental II, tendo como base de análise o estudo de um caso.

A entrevista realizada buscou, primeiramente, entender como o docente se define profissionalmente, ou seja, como constrói sua identidade, e verificamos que esta foi construída por meio de um afastamento do profissionalismo e a necessidade de traduzir a profissão em vocação, crendo assim ser capaz de mudar as crianças, ou seja, a base da sociedade.

Esta concepção messiânica, de portador de uma vocação, é o que Cortella (2011, p. 110-111) denomina de otimismo ingênuo, pois atribui à escola a capacidade de extinguir a pobreza e a miséria que não foram criadas por ela, alavancando a sociedade. Ainda, segundo ele, aparta à docência do mundo profissional.

A falta de profissionalismo é validada pela constatação que fazemos quando o professor relata que recebeu informações insuficientes para que pudesse desempenhar seu fazer pedagógico por parte do grupo gestor, mais especificamente da coordenação pedagógica.

A coordenação pedagógica é uma função desempenhada por um professor designado, que precisa estar em constante formação para ter condições de realizar a formação docente dos demais professores que atuam na escola, durantes as ATPC (Aula de Trabalho Pedagógico Coletivo) com duração de duas ou três aulas semanais.

Porém, observamos por meio da entrevista, que não há conhecimento de manuais específicos para o PAEE (Público Alvo da Educação Especial), e também de linhas teóricas que possam ser utilizadas dentro de uma metodologia específica para o desenvolvimento de aulas. Acreditamos que todos os membros da equipe gestora deveriam receber por parte dos órgãos competentes formação continuada adequada e obrigatória para subsidiar de maneira mais eficaz o desempenho de suas funções.

Quando questionamos o professor sobre a inclusão este declarou ser a favor, mas ao mesmo tempo demonstrou certo constrangimento ao admitir que talvez um "local apropriado" teria condições de desenvolver um trabalho melhor com o aluno portador de TEA. 
É importante salientar que a inclusão não se reduz a inserir tais alunos em sala de aula, o trabalho inclusivo, conforme cita Dechichi (2001), significa pensar nas necessidades de todos, não somente dos deficientes, isso por si só eliminaria a distinção que fazemos de ensino especial e ensino comum.

Percebemos que o professor, entrevistado, associa o termo inclusão a deficiência, e que se sente impotente, pois não tem conhecimento mínimo para trabalhar com o aluno portador de TEA, não fez nenhuma adaptação curricular, embora ache necessária uma metodologia diferenciada para o aluno em questão.

Segundo o professor, o conhecimento que possui acerca do aluno é que este tem 14 anos, já estudou em vários colégios, mas não conseguiu se adaptar a nenhum deles, estuda nesta escola há dois anos. Em relação às características do aluno, segundo o entrevistado o mesmo tem comunicação verbal, consegue se comunicar, porém não estabelece contato visual, não tem cuidador (apoio oferecido pelo estado para alunos que necessitam de cuidados especiais); no ano de 2015 usava protetor auricular, pois o barulho o irritava, agora não mais utiliza; também tinha crises onde gritava excessivamente, o que também melhorou sensivelmente. Tais informações demonstram o importante papel da escola no desenvolvimento, aprendizagem e na adaptação sistemática ao convívio social que tal experiência proporciona.

Entretanto, o aluno é visto pelo professor como sendo resistente e difícil de se obter respostas. As habilidades de leitura que ele possui, segundo o professor responsável pela sala de leitura, não são compartilhadas, o interesse que manifesta por leitura sobre animais também não. A falta de comunicação dentro do ambiente escolar faz com que certas habilidades deste aluno sejam negligenciadas.

$\mathrm{Na}$ maioria das vezes, o professor não consegue desenvolver um trabalho com alunos com TEA somente com boa vontade, é necessário conhecimento, comprometimento e trabalho conjunto.

No contra turno, o aluno deveria receber Atendimento Educacional Especializado - AEE, que representa um complemento da escolarização com recursos que facilitam sua aprendizagem, e todos os alunos PAEE têm direito a esse serviço, mas este atendimento foi recusado pelos pais, que optaram por um atendimento particular de um psicopedagogo, que realiza um trabalho desvinculado da escola, pois nenhuma orientação é repassada e/ou solicitada para a escola com a finalidade de um trabalho colaborativo. 
Acreditamos que faltou orientação adequada à família para que optasse por não receber o AEE, pois o trabalho realizado pelo profissional da sala de recursos contribui na elaboração de materiais adequados, estratégias de ensino e organização da sala regular, contribuindo assim para o desenvolvimento e autonomia do aluno.

Finalizamos nossa entrevista com a visão que o professor tem sobre a inclusão de alunos PAEE no ensino regular, ele transmite preocupação e angústia, por não receber orientações, e não saber como agir, acha que a escola e os docentes ainda não estão preparados.

Salientamos que, o professor deve ter consciência de que sua formação deve ser contínua e relacionada com seus desafios diários, para Nóvoa (2003, p. 23 ) “O aprender contínuo é essencial e se concentra em dois pilares: a própria pessoa, como agente, e a escola como lugar de crescimento profissional permanente".

\section{Considerações finais}

Concluímos, fazendo algumas afirmações relevantes para a inclusão escolar dos alunos com TEA. Segundo Carvalho (2014, p. 154) os professores não conhecem o texto de Salamanca, acreditam ser somente para os alunos alguma deficiência, enquanto que os envolvidos na Educação Especial não conhecem a Declaração Mundial de Educação para Todos. Esta constatação serve para nos alertar de que ambos contêm o que seria o ideal da inclusão e portanto, deveríamos conhecê-los. Afirma que: “. . . é a escola, entendida como espaço "dos escritos"; espaço de apropriação e construção de conhecimentos e não como espaço de socialização, pela convivência, apenas..." (p.155).

Com base em tal afirmação a escola inclusiva deve enxergar cada aluno com sua individualidade, de modo a perceber que cada um possui uma necessidade; conhecer a identidade de cada um, ou seja, aceitando as características pessoais distintas; buscando a equidade, dando oportunidade a todos e removendo as barreiras que impedem a construção de qualquer tipo de conhecimento.

No caso especifico dos educandos com TEA que apresentam alterações na capacidade de comunicação e interação social consequentemente, que dificulta e muito seu aprendizado, temos a citação de Rodrigues e Spencer (2010, p. 70) “as intervenções de aplicação pedagógica, pelas quais o professor confrontará na práxis a realidade dele, 
sujeito pesquisador e construtor, sujeito dirigido por suas intenções de minimizar sintomatologias, maximizando potencialidades"

Tal citação vai de encontro ao que expressa o professor quando afirma que a socialização ocorre, mas tem consciência de que isto somente é insuficiente, entretanto se sente incapaz de modificar este cenário, sente-se desamparado por parte da gestão, então acaba incorporando em seu discurso que uma sala especial teria condições mais adequadas para o aluno com TEA.

É neste contexto que entra o trabalho colaborativo entre professor, gestão e AEE a fim de pôr em prática não um currículo adaptado, mas o desenvolvimento de habilidades especificas que cada aluno TEA possui, favorecendo seu desenvolvimento e auxiliando o professor da sala regular.

É de suma importância que os professores tenham formação adequada para que, segundo Carneiro (2012), sejam capazes de analisar a própria prática e o contexto, avaliar diferentes situações de ensino, trabalhar com situações problema, utilizar um repertório variado de soluções, tomar decisões e ser responsável por elas.

Para tanto, além do docente, a gestão escolar também tem um papel fundamental na formação continuada, uma vez que a coordenação pedagógica é a responsável pela pauta das ATPC, sendo colaboradora na conexão entre teoria e pratica, com a finalidade de tornar o professor mais reflexivo e capaz de resolver as diferenças de aprendizagem dos alunos. Mas, de acordo com nosso entrevistado, a coordenação pedagógica tem boa vontade, mas falta-lhe qualificação também.

Sendo assim, a coordenação pedagógica deve ser responsável por buscar a própria formação, lendo, pesquisando, realizando cursos, refletindo, caso isto não ocorra o trabalho de formação continuada realizado nas ATPC estará comprometido. Cabendo o mesmo aos demais membros da equipe gestora, pois ao diretor cabe a responsabilidade de manter sua equipe atualizada e comprometida com a educação de todos.

Em suma, a entrevista nos mostra que o aluno com TEA consegue conviver bem com os demais alunos, e que é extremamente importante para a construção de valores em todos, dissipando preconceitos, mas que ainda falta conhecimento, comprometimento e iniciativas governamentais para que de fato tenhamos a inclusão.

O modelo de escola que reproduzimos desde 1867, onde o professor é o único que transmite a informação e os alunos a recebem, está ultrapassada, precisamos de 
espaços que sejam integrados e compartilhados. A educação precisa ser pensada para além dos prédios escolares, compreendendo toda a sociedade.

\section{REFERÊNCIAS}

CARNEIRO, R. U. C. Formação de professores: da educação especial à inclusiva alguns apontamentos. In: ZANIOLO, L. O.; Dall’Acqua, M. J. C. Inclusão Escolar: pesquisando políticas públicas, formação de professores e práticas pedagógicas. Jundiaí: Paco Editorial, 2012.

CARVALHO, R. E. Educação inclusiva: com os pingos nos “is".10aed - Porto Alegre: Mediação, 2014.

COLL, C.; PALACIOS, J.; MARCHESI, A. Desenvolvimento psicológico e educação: transtornos do desenvolvimento e necessidades educativas. v. 3. $2^{\circ}$ ed. Porto Alegre: Artmed, 2004.

CARVALHO, B. S. da S.; NASCIMENTO, L. F. do N. O autista e sua inclusão nas escolas particulares da cidade de Teresina - PI. Revista Educação Especial, v. 28, n. 53, p. 677-690, set./dez. 2015.

CORTELLA, M. S. A escola e o conhecimento: fundamentos epistemológicos e políticos. Cortez Editora, 14ª edição, p. 110-111.

DECHICHI, C. Transformando o ambiente da sala de aula em um contexto promotor do desenvolvimento do aluno deficiente mental. Tese de Doutorado. USP, São Paulo, 2001.

FONSECA, Bianca. Mediação escolar e autismo: a prática pedagógica intermediada na sala de aula. Rio de Janeiro. Wak. Editora, 2014.

GAUDERER, E. C. Autismo e outros atrasos do desenvolvimento: uma atualização para os que atuam na área: do especialista aos pais. Brasília: CORDE, 1993.

KANNER. Affective disturbances of affective contact. Nervous Child, v.2, p.217-250, 1943.

LUDKE, M.; ANDRÉ, M. E. D. A. Pesquisa em educação: abordagens qualitativas. São Paulo: EPU, 1986.

NÓVOA, A. Escola nova. A revista do professor. Ed. Abril, 2002, p,23.

RODRIGUES, J. M. C.; SPENCER, E. A criança autista: um estudo psicopedagógico. Rio de Janeiro. Wak. Editora, 2010.

SCHWARTZMAN, J. S. Autismo infantil. Brasília: CORDE, 1994. 
STAINBACK, S.; STAINBACK, W.; Inclusão: um guia para educadores. Trad. Magda França Lopes. Porto Alegre: Artes Médicas Sul, 1999.

\section{Como referenciar este artigo}

CÁBRIO, Regiane Cristina.; CARNEIRO, Relma Urel Carbone. Inclusão escolar de estudantes com transtorno do espectro autista (TEA) no ensino fundamental II. Temas em Educ. e Saúde, Araraquara, v.13, n.2, p. 260-270, jul./dez. 2017. Disponível em: <https://doi.org/10.26673/rtes.v13.n2.jul-dez.2017.9549>. E-ISSN: 2526-3471.

Submetido em: 22/03/2017

Aprovado em: 28/09/2017 